\title{
Superfine powdered activated carbon (S-PAC) coatings on microfiltration membranes: Effects of milling time on contaminant removal and flux
}

Pauline Amaral ${ }^{a}$, Erin Partlan ${ }^{\mathrm{b}}$, Mengfei Li ${ }^{\mathrm{b}}$, Flavio Lapollia, O. Thompson Mefford $^{\mathrm{c}}$, Tanju Karanfil ${ }^{\mathrm{b}}$, David A. Ladner ${ }^{\mathrm{b} *}$

aDepartment of Environmental and Sanitary Engineering, Federal University of Santa Catarina, Campus Reitor João David Ferreira Lima, s/n, Trindade, Florianópolis, SC 88040-900, Brazil.

${ }^{\mathrm{b}}$ Department of Environmental Engineering and Earth Sciences, Clemson University, 342 Computer Ct, Anderson, SC, 29625, USA.

'Department of Materials Science and Engineering, 161 Sirrine Hall, Clemson University, Clemson, SC 29634, USA.

*Corresponding author: ladner@clemson.edu

1

2

3

4

5

6

7

8

\section{Abstract}

In microfiltration processes for drinking water treatment, one method of removing trace contaminants is to add powdered activated carbon (PAC). Recently, a version of PAC called superfine PAC (S-PAC) has been under development. SPAC has a smaller particle size and thus faster adsorption kinetics than conventionally sized PAC. Membrane coating performance of various S-PAC samples was evaluated by measuring adsorption of atrazine, a model micropollutant. S-PACs were created in-house from PACs of three different materials: coal, wood, and coconut shell. Milling time was varied to produce SPACs pulverized with different amounts of energy. These had different particles sizes, but other properties (e.g. oxygen content), also differed. In pure water the coal based S-PACs showed superior atrazine adsorption; all milled carbons had over $90 \%$ removal while the PAC had only $45 \%$ removal. With addition of calcium and/or NOM, removal rates decreased, but milled carbons still removed more atrazine than PAC. Oxygen content and specific external surface area (both of which increased with longer milling times) were the most significant predictors of atrazine removal. S-PAC coatings resulted in loss of filtration flux compared to an uncoated membrane and smaller particles caused more flux decline than larger particles; however, the data suggest that NOM fouling is still more of a concern than S-PAC fouling. The addition of calcium improved the flux, especially for the longer-milled carbons. Overall the data show that when milling S-PAC with different levels of energy there is a tradeoff: smaller particles adsorb contaminants better, but cause greater flux decline. Fortunately, an acceptable balance may be possible; for example, in these experiments the coal-based SPAC after 30 minutes of milling achieved a fairly high atrazine removal (overall $80 \%$ ) with a fairly low flux reduction (under $30 \%$ ) even in the presence of NOM. This suggests that relatively short duration (low energy) milling is viable for creating useful S-PAC materials applied in tandem with microfiltration.

Keywords: activated carbon, contaminant, milling time, microfiltration membranes 


\section{Introduction}

Activated carbon adsorption is a common and generally effective treatment method for removing small molecular weight organic compounds in water treatment plants (Kemmer, 1988; Crittenden et al., 2012). Most commercial carbons are produced from naturally occurring carbonaceous materials, such as coal, oil, peat, coconut shell and wood, by chemical or thermal activation of carbonized material. Activated carbon can be applied in powdered (PAC) or granular (GAC) form (Snoeyink \& Chen, 1985; Wigmans, 1989). A more recent approach in carbon adsorption is the use of its superfine powdered form (S-PAC) produced by grinding PAC until its particle size has been reduced to near or below one micrometer (Partlan et al., 2015).

The motivation behind S-PAC is an improved adsorbate uptake rate, since smaller carbon particles have faster adsorption kinetics than larger carbon particles (Najm et al., 1990). The faster adsorption kinetics can be explained by a shorter travel distance for intraparticle radial diffusion in the smaller particles (Sontheimer et al., 1988; Matsui et al., 2009). Studies showed a better adsorbate uptake rate by S-PAC, when compared with PAC, of compounds such as geosmin, 2-methylisoborneol (MIB), atrazine, and natural organic matter (NOM) (Heijman et al., 2009; Matsui et al., 2009, 2012, 2013; Ando et al., 2010; Ellerie, et al., 2013).

We recently examined the effects of varied milling time by pulverizing PAC into S-PAC with a bead mill (MiniCer, Netzsch Premier Technologies, Exton, PA, USA) for different lengths of time while holding recirculation flow rate and mill rotational speed constant (Partlan et al., 2015). Adjusting milling time is a convenient way to vary the energy received by each carbon sample; thus, we 
examined the effects of varying energy of pulverization; in our discussion milling time is a surrogate for energy input. Other milling machines operated with different rotational speeds and flow rates would, of course, impart different energies than in this study. Our previous work treats this topic in some detail (Partlan et al., 2015). In addition to particle size reduction, the milling process may cause several other physicochemical changes that also impact the adsorption performance, such as shifts in oxygen content and $\mathrm{pH}$. An increase in oxygen content can result in decreased adsorption of organic compounds by activated carbons (Karanfil et al., 1999; Considine et al., 2001). The $\mathrm{pH}_{\mathrm{pzc}}$ values indicate the acidity/basicity characteristics of the carbon, which affect preferential adsorption with respect to adsorbate charge (Dastgheib et al., 2004).

One of the challenges of working with S-PAC is the removal of such small particles from water after the adsorption process. PAC removal is usually done through coagulation/flocculation, sedimentation, and granular media filtration. Membrane filtration is also effective for PAC, though the membrane module and process design should be engineered to accommodate PAC presence (Chang et al., 2005; Kim et al., 2005; Gai \& Kim, 2007; Damayanti et al., 2011; Khan et al., 2011). When using membranes to remove S-PAC, a cake layer is formed from the accumulation of particles on the membrane surface. This layer can also be applied intentionally to serve as a thin adsorption column (Heijman et al., 2009; Ellerie et al., 2013). The pre-coat is responsible for a significant amount of micropollutant removal and can also protect the membrane from fouling, since the foulant is adsorbed or attached to the pre-coat before it can reach the membrane. PAC particle sizes are large enough that membrane pores are not blocked, but smaller particles, such as S-PAC, can block pores and/or form a 
layer of relatively low permeability that can cause flux decline (Yiantsios \&

81 Karabelas, 2001; Williams et al., 2005; Ando et al., 2010; Ellerie et al., 2013).

One obvious engineering goal is to use S-PAC particles that are small enough to achieve good adsorption kinetics, but large enough to prevent significant flux reduction. Matsui et al. (2009), found that S-PAC with a median diameter of 0.88 $\mu \mathrm{m}$ did not reduce membrane permeability of MF ceramic membranes with nominal pore size of $0.1 \mu \mathrm{m}$; in fact, it alleviated long term trans-membrane pressure buildup by removing foulants that contribute to hydraulically irreversible fouling. Further studies are needed to evaluate how particles of various size and material properties contribute to membrane fouling, and how this can be mitigated while still achieving good micropollutant removal.

Another consideration while using activated carbon in water treatment is competition from NOM adsorption. One of the drawbacks of PAC is that micropollutant adsorption capacity can be dramatically reduced in the presence of NOM due to pore blockage by high molecular weight (MW) NOM and by loading of low MW NOM onto the intraporous adsorption sites of PAC (Kilduff et al., 1998). NOM competition can be important since the NOM concentration in natural waters is typically several orders of magnitude higher than the concentration of micropollutants. S-PAC typically has a higher adsorption capacity for NOM than PAC due to a higher specific external surface area; NOM molecules do not completely penetrate the adsorbent particle but instead preferentially adsorb near the exterior particle surface (Matsui et al., 2004, 2011, 2012; Ando et al., 2010).

The objective of this paper is to understand how the performance of adsorptive activated carbon membrane coatings is affected by physicochemical changes in 
105 the carbon when milled to small sizes. While the primary outcome of milling is 106 physical particle size reduction, secondary effects to the carbon surface 107 chemistry can affect interactions with adsorbate chemistry and affect particle 108 stability, which impacts coating formation. Coatings are evaluated for fouling 109 propensity via decline in flux over filtration time, and for adsorption performance 110 via contaminant presence in the membrane permeate. Lastly, we varied the water 111 matrix, including the addition of hardness via calcium, to evaluate applications to 112 drinking water treatment scenarios.

113 2. Materials and Methods

\section{$114 \quad 2.1$ Adsorbents}

115 Three commercially available activated carbon materials were chosen for 116 comparison in this study: WaterCarb-800 (bituminous coal, Standard 117 Purification), Aqua Nuchar (wood, Mead Westvaco) and Aquacarb 1230C 118 (coconut shell, Siemens), referred to as BC, WD and CS respectively.

119 The S-PAC was produced from the corresponding PAC using a wet bead mill 120 (MiniCer, Netzch Premier Technologies, Exton, PA, USA) containing 0.3-0.5 mm 121 yttrium-stabilized zirconium oxide ceramic beads. Passing one batch of PAC 122 slurry through the mill required 45 seconds, which corresponded with 123 approximately six seconds of residence time for any given particle in the mill. The 124 total milling time (the time spent recirculating slurry through the mill) was varied, 125 ranging from one pass to six hours for $B C$ and WD carbons and from one pass 126 to four hours for CS carbon.

127 Material characteristics and characterization methods for these PACs and S128 PACs were reported previously (Partlan et al., 2015). For particles smaller than $1296 \mu \mathrm{m}$, size distributions were determined by dynamic light scattering (DLS) using 
a Zetasizer NanoZS (Malvern, Worcestershire, UK). Particles larger than $6 \mu \mathrm{m}$

131 were measured by optical microscopy imaging using a Zeiss Axioskop 2 Plus optical microscope (40x objective lens) with a Zeiss AxioCam MRc5 camera attachment running AxioVision AC version 4.2 software. Surface area was calculated with the Brunauer-Emmett-Teller (BET) equation, using the $\mathrm{N}_{2}$ physisorption data at 77K obtained with an ASAP 2020 analyzer (Micromeritics Instrument Corp. U.S). The $\mathrm{pH}$ at which the adsorbent surface had net zero charge $\left(\mathrm{pH}_{\mathrm{pzc}}\right)$ was determined using the $\mathrm{pH}$ drift method. In this method, for each $\mathrm{pH}$ tested, $100 \mathrm{mg}$ of dry carbon was contacted with $20 \mathrm{~mL}$ of $\mathrm{pH}$-adjusted $0.1 \mathrm{M}$ $\mathrm{NaCl}$. After a minimum of 48 hours on a shaker table $\mathrm{pH}$ was measured in the sample vial and compared to a no carbon blank vial. The measurement of weight percent of oxygen was performed using a Flash Elemental Analyzer 1112 series and S-PACs.

Surface area, external surface area, particle size, $\mathrm{pH}_{\mathrm{pzc}}$ and oxygen content for all PACs and S-PACs are shown in Table 1. We use the milling time as the designation for each sample in our discussion; the reader is referred to Table 1 to connect these milling time designations with the sample properties.

\subsection{Filtration through Membrane Coatings}

150 The direct-flow MF setup consisted of an $800 \mathrm{~mL}$ capacity pressure vessel that 151 held the feed solution, a $10 \mathrm{~mL}$ membrane cell (Amicon, Millipore) containing the MF membrane and mesh support material, a flask for permeate collection, and a balance connected to a computer to monitor flux (Fig. 1). Pressure for filtration, fixed at 10 psi, was supplied by a nitrogen tank connected to the pressure vessel. 
155 The membranes were hydrophilic PVDF (Millipore VVLP) with $0.1 \mu \mathrm{m}$ pore size

156 and $2.5 \mathrm{~cm}$ diameter $(2.1 \mathrm{~cm}$ active diameter when installed in the filtration cell);

157 each membrane was soaked in distilled and deionized (DDI) water overnight

158 before use. The uncoated membrane flux was determined via DDI water filtration

159 for 20 minutes. A stock solution of $2000 \mathrm{mg} / \mathrm{L} \mathrm{S-PAC}$ in deionized water was used

160 for carbon addition. Aliquots of $40 \mathrm{~mL}$ stock solution were sonicated for 4 minutes

161 with a probe sonicator at 50\% power (S-4000, Qsonica, LLC), before addition to

162 ensure disaggregation. An appropriate volume of the sonicated stock solution to

163 achieve the desired carbon mass was added to water directly in the membrane

164 cell without a stirring system. The filtration process caused the particles to

165 accumulate on the membrane surface forming a non-rigid carbon layer. The

166 carbon mass added to the membrane cell was 1, 2 and $4 \mathrm{mg}$, depending on the

167 experiment.

168 In each experiment $400 \mathrm{~mL}$ of feed solution was filtered and the permeate was 169 collected in $20 \mathrm{~mL}$ glass vials. Samples for analysis were prepared by mixing two 170 consecutive $20 \mathrm{~mL}$ vials, then pulling $5 \mathrm{~mL}$ out for further analysis (described 171 below); ten such samples were measured per filtration.

\section{$172 \quad 2.3$ Feed Water Composition}

173 The herbicide atrazine was chosen as the model micropollutant for this study.

174 Atrazine is one of the most widely used herbicides in the world; due to his high

175 mobility in soil, atrazine and its metabolites are commonly found in ground water, 176 surface water and drinking water supplies (Pereira \& Rostad, 1990; Koplin et al., 177 1997; Brown et al., 2004; Graziano et al., 2006). Several studies have been 178 conducted aiming to improve the removal efficiency of this compound from water 
179 (Berg et al., 1997; Li et al., 2003; Yoon et al., 2006; Jia et al., 2006; Chen et al. 180 2009), which allows a comparison with the S-PAC data presented here.

181 Atrazine is a hydrophobic compound with a moderate water solubility $\left(\mathrm{S}_{\mathrm{w}}=30\right.$ $182 \mathrm{mg} / \mathrm{L})$, low octanol/water partition $\left(\log \mathrm{K}_{\mathrm{ow}}=2.75\right)$ and electron rich nitrogen and 183 chlorine groups that make it polar (Colombini et al., 1998). The atrazine 184 concentration in the feed solution was $15 \mu \mathrm{g} / \mathrm{L} .{ }^{14} \mathrm{C}$ labeled atrazine, with a 185 specific activity of $160 \mathrm{mCi} / \mathrm{mmol}$ (American Radiolabeled Chemicals, Inc), was 186 used as a tracer among non-labeled atrazine (Accustandard) in a ratio of 1:300. 187 Radioactivity was measured by liquid scintillation counting (LSC) (Tri-Carb B2910TR, PerkinElmer) of samples mixed 1:1 with scintillation cocktail 189 (UltimaGold XR). The detection limit of the method was approximately $0.07 \mathrm{ppb}$.

190 Suwannee River NOM (SRNOM) (International Humic Substances Society, 191 Golden, Colorado) was used as the primary NOM source. SRNOM stock solution 192 (500 mg/L) was prepared in DDI water and filtered through a $0.15 \mu \mathrm{m}$ microfiber 193 ionic strength; $\mathrm{NaCl}$ was reduced in these cases to maintain a total ionic strength of $10 \mathrm{mM}$. The $\mathrm{pH}$ of all solutions was adjusted to $7.0 \pm 0.1$ with $\mathrm{HCl}$ or $\mathrm{NaOH}$ as required.

200 Water from the Edisto river (South Carolina, US) was used in some experiments 201 as a natural water source. The DOC concentration was approximately $6.5 \mathrm{mg} / \mathrm{L}$, 202 and the water was filtered by microfiber filters (Whatman) to remove suspended 
particles before use. In experiments with SRNOM and Edisto water, DOC was measured with a Shimadzu TOC-VCHS analyzer.

\subsection{Batch Adsorption Kinetics}

206 Bottle point kinetic experiments were performed with atrazine and BC carbon. In 207 each experiment, $200 \mathrm{~mL}$ of the solution containing $15 \mu \mathrm{g} / \mathrm{L}$ of atrazine, with and 208 without SRNOM (8 mg/L), were contacted with $2.5 \mathrm{mg} / \mathrm{L}$ of carbon in $250 \mathrm{~mL}$ 209 glass bottles with Teflon-lined screw caps. The bottles were mixed on a benchtop shaker. Samples were taken every five minutes for the first 30 minutes and every 30 minutes after that for a total time of four hours. Carbon was promptly removed 212 from samples via filtration through a $0.15 \mu \mathrm{m}$ microfiber filter (Whatman), with 213 membrane retention of less than $2 \%$ of the atrazine.

214 3. Results and discussion

\section{$215 \quad 3.1$ Flux Decline}

216 In DDI, membrane coatings with BC S-PACs resulted in little loss of flux, only 1217 14\%, except for BC-6 hrs, which resulted in 55\% flux decline. Flux reduction was 218 higher when SRNOM was present (Fig. 2a). BC PAC had a flux reduction of $27 \%$, 219 around the same as BC-1 Pass (27\%), BC-15 min (27\%), BC-30 min (29\%), as 220 well as the uncoated membrane (23\%). Thus, SRNOM was the main driving force 221 for flux decline, not the carbon particles. BC-2 hrs and BC-6 hrs had very 222 accentuated flux decline, $76 \%$ and $84 \%$ respectively, which was significantly higher than their flux declines without SRNOM.

224 The addition of calcium improved flux in the presence of NOM (Fig. 2b). Calcium 225 improved the BC-2 hrs flux decline from around $75 \%$ to $25 \%$, and even the most 226 heavily fouling carbon, BC-6 hrs, saw improvement from $84 \%$ to $77 \%$. This 227 improvement would not be expected since many researchers (Hong \& Elimelech, 
1997; Zhu \& Elimelech, 1997; Seidel \& Elimelech, 2002; Li \& Elimelech, 2006)

229 pointed out that the presence of divalent ions may add to the development of 230 fouling by NOM. Calcium has a strong potential to complex with NOM and is 231 capable of forming bridges between the membrane surface and NOM (Li \& 232 Elimelech, 2004; Listiarini et al., 2009). With regard to membrane coatings, we speculate that the flux improvement may be due to the carbon layer acting as a 234 protective barrier and absorbing some of the NOM, thus not allowing it to reach 235 the membrane and cause flux decline. In addition to facilitating NOM coiling for 236 access to internal pores, calcium can also enhance NOM adsorption by acting as 237 a bridge between NOM and the carbon in the same way as the NOM-membrane bridge, which allows for adsorption of NOM aggregates onto carbon. These mechanisms also explain the decrease in atrazine removal and slight increase in NOM removal by the carbon in the presence of both NOM and calcium.

SEM images were taken of membranes coated with BC-1 Pass and BC- 6 hrs that filtered feed solutions containing atrazine in a mild $\mathrm{NaCl}$ solution (Fig. 3). The carbon deposition is visible on the membrane surface, especially for images (a) and (c) which show the entire membrane thickness. The difference in the carbon layer formation between the two S-PACs is clear; the small particles of BC-6 hrs compressed to form a compact cake layer, while BC-1 pass with larger particles did not form a tight cake.

Particle size was an important parameter for the S-PAC coated membrane permeate flux decline. The data discussed above in Fig. 2 showed that the longest milling time had the greatest flux decline in the BC carbon case. When 251 plotted with particle size explicitly on the X-axis (Fig. S1) we can observe the flux 252 vs. particle-size relationship and make a direct comparison with the WD and CS 
carbons. All carbon types showed a much lower average permeate flux with the smallest particles (longest milling times). For the other milling times, there is a general trend of higher flux with higher particle size (though WD-1 Pass is an outlier). It is noteworthy that the trend is not linear; there seems to be a size threshold where flux decline is suddenly intense for the smallest particles, and that threshold depends on carbon type. This suggests that as long as the particle size remains above a certain value, one can gain the adsorption benefits of smaller particle size without paying a significant penalty in flux decline. The adsorption (i.e. contaminant removal) benefits are described in the following section.

When increased masses of carbon were used to coat the membrane, changes in flux decline were relatively minimal; membranes coated with $4 \mathrm{mg}$ of BC PAC, BC-1 Pass and BC-6 hrs had almost the same flux decline as the corresponding $1 \mathrm{mg}$ coating, while other carbons resulted in slight increases (Fig. S2). The largest increase was from $27 \%$ with $1 \mathrm{mg}$ to $55 \%$ with $4 \mathrm{mg}$ using BC-2 hrs.

\subsection{Contaminant Removal}

For every condition studied and for each carbon tested, the atrazine removal by S-PACs was superior to the respective parent PACs. Feed solutions containing atrazine in a) DDI, b) SRNOM, and c) SRNOM with $\mathrm{Ca}^{2+}$ were filtered through 1 mg of BC coated on an MF membrane (Fig. 4). Controls revealed that uncoated membranes adsorbed at most $20 \%$ of atrazine, depending on the water composition. In DDI water, BC PAC had high initial atrazine adsorption, 92\%; however, the retention dropped to $50 \%$ after filtering $200 \mathrm{~mL}$ and to only $15 \%$ after filtering $400 \mathrm{~mL}$ for an overall removal of 45\% (Fig. 4a). BC S-PACs removed more than $90 \%$ of atrazine on average, reaching $99 \%$ for BC-15 min, BC-30 min, 
278 BC-1 hr and BC-6 hrs. These results are consistent with previous studies that 279 show faster adsorption onto S-PAC due to its smaller size (Ando et al., 2010; 280 Ellerie et al., 2013; Matsui et al., 2013).

In the presence of SRNOM, the atrazine retention increased with milling time, except for BC-6 hrs (Fig. 4b). BC PAC, BC-1 Pass, BC-15 min and BC-30 min showed high initial atrazine removal that decreased over the course of filtration. 284 BC-1 hr and BC-2 hrs had consistent atrazine removal over the course of 285 filtration, with an overall removal of 95\% each. Similar results were observed in experiments using Edisto River water instead of SRNOM; again, atrazine removal increased with milling time except for BC-6 hrs (Fig. S3). These data are consistent with a previous report where better atrazine retention was achieved by performance.

With the addition of calcium, atrazine broke through earlier (Fig. 4c). BC PAC

S-PAC membrane coatings in water containing NOM (Heijman et al., 2009). The results of this study confirm that size is the dominant factor in atrazine removal

only removed $7 \%$ of the atrazine with no atrazine removal after $200 \mathrm{~mL}$ filtered. Again, atrazine removal increased with milling time, except for BC-6 hrs, from 24\% (BC-1 Pass) to 81\% (BC-2 hrs). The decrease of atrazine removal in this case may be related to coiled NOM. Some authors (Braghetta et al., 1997; Leenheer, 2007) state that NOM macromolecules may change shape, including coiling and uncoiling, as a function of $\mathrm{pH}$, ionic strength and interactions with cations and minerals. Coiling can occur when calcium complexation causes reduced electrostatic repulsion among the branches of NOM macromolecules (Hong \& Elimelech, 1997). The coiled NOM is smaller and can reach deeper into 
302 the carbon internal pores, thus competing more readily with atrazine for 303 adsorption sites or blocking atrazine out the pores.

304 Filtration experiments performed with additional carbon types exhibited varied 305 results. WD showed no correlation between milling time and atrazine removal; 306 the highest atrazine removal was obtained with WD-10 min and WD-20 min, 58\% 307 and 55\%, and the lowest, 18\%, was obtained with WD-5 min (Fig. 5a). CS 308 of $13 \%$ with the parent PAC to $93 \%$ with CS-4 hrs (Fig. 5b).

Atrazine concentrations were measured during the increased carbon mass trials where $2 \mathrm{mg}$ and $4 \mathrm{mg}$ of $\mathrm{BC}$ carbon were used in water containing SRNOM and calcium (Fig. S4). BC PAC had ten times higher atrazine removal with $4 \mathrm{mg}$ than with $1 \mathrm{mg}$, and BC-1 Pass had twice the removal with $2 \mathrm{mg}$ as $1 \mathrm{mg}$ and an additional 50\% removal from $2 \mathrm{mg}$ to $4 \mathrm{mg}$. The other BC S-PACs achieved more than 90\% atrazine removal with $2 \mathrm{mg}$, which is a significant improvement considering $\mathrm{BC}-15 \mathrm{~min}, \mathrm{BC}-30 \mathrm{~min}$ and $\mathrm{BC}-6 \mathrm{hrs}$ had an overall removal below $70 \%$ with the $1 \mathrm{mg}$ coating, though the $4 \mathrm{mg}$ coating did not result in additional removal (Fig. S4a, Fig S4b). Removal of NOM did not change with increased carbon mass and was generally minimal (Fig. S4c, Fig. S4d).

Results of removals through carbon coatings are in agreement with batch adsorption kinetics that showed high atrazine adsorption onto S-PAC under very short contact times (Fig. 6). In DDI water, BC PAC showed 61\% atrazine removal within 5 minutes, BC-1 Pass had 73\%, and other S-PACs had over 97\% removal 324 (Fig. 6a). Similar results were seen in the presence of NOM; within 5 minutes, BC PAC had 28\% atrazine removal, while BC-30 min, BC-1 hr, BC-2 hrs and BC-6 hrs had near or over $90 \%$ atrazine removal (Fig. 6b). These results support the 
327 idea that faster adsorption kinetics is the mechanism behind the enhanced 328 contaminant removal observed in membrane coatings with smaller S-PAC 329 particles.

330 For all carbons, the atrazine adsorption uptake was smaller in SRNOM331 containing water. The presence of SRNOM reduced the atrazine removal by BC332 PAC around 35\% and by BC S-PAC about 48\% (1 Pass), 17\% (15 min), 13\% (30 $333 \mathrm{~min}$ ), 4\% (1 hours), 3\% (2 hours) and 36\% (6 hours). Those results indicate that 334 NOM competition is less intense for most of the S-PACs.

NOM adsorption, either from the SRNOM source or the Edisto River water, was not found to be significantly higher on S-PAC than PAC (Fig. S5 and Fig. S6). At equilibrium, NOM can be expected to have a larger adsorption capacity on SPAC since NOM mainly adsorbs close to the external adsorbent particle surface and does not completely penetrate into internal pores (Ando et al., 2010, 2011; Matsui et al., 2011). However, here, under high NOM concentrations and short contact times, the unchanged NOM adsorption rate and increased atrazine adsorption rate results in reduced NOM competition with S-PAC, probably because there were more pores available than in PAC.

\subsection{Adsorbent Properties Influencing Performance}

In order to elucidate the key S-PAC properties that affect performance, atrazine removal was correlated against physical and chemical properties of S-PAC, 347 including oxygen content, specific surface area, particle size, and specific external surface area. In drinking water treatment, effects of adsorbent surface chemistry are important since adsorption proceeds via displacement of the existing water-covered surface by the dissolved pollutant molecules (Pendleton 351 et al., 1997). 
352 For a $1 \mathrm{mg}$ coating of BC, CS, and WD PAC and S-PACs, atrazine removal 353 correlated most strongly with specific external surface area, and less with the 354 other measurements (Fig. 7). Oxygen content increased with milling time for the 355 carbons BC, WD and CS, which was a result of external surface oxidation likely 356 originating from a highly abrasive milling environment (Partlan et al., 2015). The 357 oxygen content density, that is the oxygen content normalized to the external 358 surface area, is consistent among S-PACs. Oxygen content was the best single 359 predictor of CS atrazine adsorption (Fig. 7a). BC and WD results are consistent with those presented by Yu et al. (2007); for MIB and geosmin adsorption on a carbon with a broad pore volume distribution, they saw no statistically significant correlation between the adsorption capacity and the carbon's oxygen content or surface functional groups.

Though surface area typically correlates with increased adsorption capacity, 365 several studies also found that higher surface area does not always result in higher removal efficiency of the carbon (Mondal et al., 2015; Liu et al., 2013; Sardella et al., 2015; Hadi et al., 2015). WD had the highest surface area, approximately $1500 \mathrm{~m}^{2} / \mathrm{g}$ compared to $1000 \mathrm{~m}^{2} / \mathrm{g}$ or less in BC and CS carbons, as well as the largest change with milling time, losing $500 \mathrm{~m}^{2} / \mathrm{g}$ over 6 hours of milling, but these changes did not correlate with WD atrazine removal (Fig. 7b).

Atrazine adsorption increased with the decreased particle size between PAC and S-PAC, where removals increased from $20 \%$ to $99 \%$, but correlated less so among S-PACs (Fig. 7c). Specific external surface area, as calculated from particle size measurements, proved to be the best predictor of atrazine removal 375 on BC S-PACS and WD S-PACs, despite a poor correlation due to one outlier 376 data point for WD, as well as a fair predictor of CS S-PACs (Fig. 7d). 
377 Multiple linear regression analysis was used to predict atrazine removal from

378 these four parameters. A significant regression equation was found $(F(3,17)=$

$37915.64, p<0.0001)$, with an $R^{2}$ of 0.734 . Atrazine removal was predicted by 15.89

$380+0.04(\mathrm{OXY})+5.98\left(\mathrm{SA}_{\mathrm{ext}}\right)-1.26(\mathrm{OXY}-5.62)\left(\mathrm{SA}_{\mathrm{ext}}-5.34\right)$ where oxygen content

$381(\mathrm{OXY})$ is measured in weight percent oxygen and specific external surface area 382 is measured in $\mathrm{m}^{2} / \mathrm{g}$. Oxygen content and specific external surface area are 383 correlated with each other since it is expected that the majority of new oxygen is 384 attached to the external surfaces only (Partlan et al., 2015). With these two 385 parameters as the most significant predictors of atrazine removal, the model 386 suggests that interactions at the external surface may be the most crucial 387 component of the adsorption pathway. In regards to membrane filtration with contaminants contact first as they travel through the adsorbent layer.

\subsection{Tradeoffs between contaminant removal and energy requirements}

392 The benefits of carbon particle size reduction to increased atrazine removal are 393 countered by the increased energy requirements of producing the S-PACs and 394 increased cost of application due to higher head loss. To evaluate S-PAC efficiency, atrazine removal for each S-PAC is compared with the permeate flux of coated membranes as well as production energy, given that milling time is linearly related to energy input. The best scenario would require minimal processing, result in minimal flux decline, and provide high atrazine removal. $\mathrm{BC}$ S-PACs milled for 15 minutes and 30 minutes showed atrazine removal over $60 \%$ and a relatively low flux decline (Fig. 8). WD also showed a good balance between atrazine removal and permeate flux at lower milling times; WD-10 min 
402 was the most favorable WD S-PAC. CS S-PACs also followed this pattern, with 403 CS-20 min as the most favorable S-PAC due to flux decline, but it did not have 404 the highest atrazine removal, which was achieved with CS-4 hrs and a flux decline of $70 \%$. Additional milling times for CS may reveal an ideal milling time between 20 minutes and 4 hours. Overall, BC-15 min and BC 30-min had the best performance in this sample set; they showed high atrazine removal 408 combined with lower energy input.

\section{Conclusions}

410 The main conclusions from this study are as follows:

- Rapid adsorption onto S-PAC allows for the creation of useful adsorbent membrane coatings. All S-PAC coatings removed atrazine better than the parent PAC coatings regardless of NOM or calcium presence.

- Oxygen content and specific external surface area (both of which increased with longer milling times) were the most significant predictors of atrazine removal. The two are correlated, since oxygen increases preferentially on the external surfaces.

- Membrane coating performance depended heavily on water quality. NOM caused increased flux decline and also lowered atrazine removal. It is important to note that the NOM was the main cause of fouling in most cases, rather than the S-PAC. If this is true at full scale, it bodes well for this hybrid process, as the fouling from S-PAC addition may be inconsequential compared to the fouling already present.

- Calcium resulted in improved flux in the presence of NOM because calcium aided the capture of NOM in the carbon layer, rather than allowing 
426 it to reach the membrane. Calcium also resulted in less atrazine removal, demonstrating a tradeoff between NOM aggregation/capture and trace contaminant removal.

- An ideal particle size balances an increased adsorption rate with

\section{Acknowledgment}

437 The authors acknowledge financial support from the National Science Foundation 438 under grant number CBET-1236070. Pauline Amaral was supported by CAPES 439 Foundation - Brazilian Federal Agency for Support and Evaluation of Graduate 440 Education within the Ministry of Education of Brazil. SEM images were created at 441 the Clemson University Electron Microscopy Laboratory. Yiran Ren is thanked for 442 her help with the milling process and with characterization analyses. Kathleen 443 Davis and Ian DeMass are also thanked for their help with characterization 444 analyses. 
Ando, N., Matsui, Y., Matsushita, T., Ohno K., 2011.Direct observation of solid-phase adsorbate concentration profile in powered activated carbon particle to elucidate mechanism of high adsorption capacity on superpowered activated carbon. Water Research 45, 761-767.

Ando, N., Matsui, Y., Kurotobi, R., Nakano, Y., Matsushita., T., Ohno, K., 2010.Comparison of natural organic matter adsorption capacities of superpowdered activated carbon and powdered activated Carbon. Water Research 44, 4127-4136.

Braghetta, A., DiGiano, F. A., Ball, W., 1997. Nanofiltration of Natural Organic Matter: $\mathrm{pH}$ and ionic strength effects. Journal of Environmental Engineering 123, 628-641.

Berg, P., Hagmeyer, G., Gimbel, R., 1997. Removal of pesticides and others micropollutants by nanofiltration. Desalination 113, 205 - 208.

Brown, N. W., Roberts, E. L. P, Chasiotis, A., Cherdron, T., Sanghrajka, N., 2004. Atrazine removal using adsorption and electrochemical regeneration. Water Research 30, $3067-3074$.

Chang, S., Waite., T. D., Fane, A. G., 2005. A simplified model for trace organics removal by continuous flow PAC adsorption/submerged membrane processes. Journal of Membrane Science 253, 81-87.

Chen, G., Shan, X., Zhou, Y., Shen, X., Huang, H., Khan, S. U., 2009. Adsorption kinetics, isotherms and thermodynamics of atrazine on surface oxidized multiwalled carbon nanotubes. Journal of Hazardous Materials 169, 912-918.

Colombini, M.P., Fuoco, R., Giannarelli, S., Pospisil, L., Trskova, R., 1998. Protonation and degradation reactions of s-triazine herbicides. Microchemical Journal 59, 239-245.

Considine, R., Denovel, R., Pendleton, P., Schumann, R., Wong, S. H., 2001. The influence of surface chemistry on activated carbon adsorption of 2-methylisoborneol from aqueous solution. Colloids and surfaces A: Physicochemical and engineering aspects179, 271-280.

Crittenden, J.C., Trussell, R.R., Hand, D.W., Howe, K.J.,Tchobanoglous, G. Water Treatment Principles and Design, 3rd ed. MWH, John Wiley \& Sons, Inc., Hoboken, Jew Jersey, 2012.

Damayanti, A., Ujang Z., Salim, M. R., 2011. The influenced of PAC, zeolite, and Moringa oleifera as biofouling reducer (BFR) on hybrid membrane bioreactor of palm oil mill effluent (POME). Bioresource Technology 102, 4341-4346

Dastgheib, S. A., Karanfil, T., Cheng, W., 2004. Tailoring activated carbons for enhanced removal of natural organic matter from natural waters. Carbon 42, 547-557.

Ellerie, J. R., Apul, O. G., Karanfil, T., Ladner D. A., 2013. Comparing graphene, carbon nanotubes, and superfine powdered activated carbon 
as adsorptive coating materials for microfiltration membranes. Journal of Hazardous Materials 261C, 91-98.

Gai, X.J., Kim, H.S., 2007. The role of powdered activated carbon in enhancing the performance of membrane systems for water treatment. Desalination 225, 288-300.

Graziano, N., MCguire, M. J., Roberson, A., Adams, C., Jiang., H., Blute, N. 2006. 2004 National atrazine occurrence monitoring program using the Abraxis ELISA method. Environ. Sci. Technol. 40, 1163-1171.

Hadi, P., Xu, M., Ning, C., Lin, C., McKa, G., 2015. A critical review on preparation, characterization and utilization of sludge-derived activated carbons for wastewater treatment. Chemical Engineering Journal 260, 895-906.

Heijman, S. G. J., Hamad, J. Z., Kennedy, M. D., Schippers, J., Amy, J., 2009. Submicron powdered activated carbon used as a pre-coat in ceramic microfiltration. Desalination and Water Treatment 9, 86-91.

Hong, S., Elimelech, M., 1997. Chemical and physical aspects of natural organic matter (NOM) fouling of nanofiltration membranes. Journal Membrane Science 132, 159-181.

Jia, Y., Wang, R., Fane, A. G., 2006. Atrazine adsorption from aqueous solution using powdered activated carbon - Improved mass transfer by air bubbling agitation. Chemical Engineering Journal 116, 53-59.

Khan, M. M. T., Takizawa, S., Lewandowski, Z., Jones, W. L., Camper, A. K., Katayama, H., Kurisu, F., Ohgaki, S., 2011. Membrane Fouling due to dynamic particle size changes in the aerated hybrid PAC-MF system. Journal of Membrane Science, 371, 99-107.

Karanfil, T., Kitis, M., Kilduff, J. E., Wigton, A., 1999. Role of Granular Activated Carbon Surface Chemistry on the Adsorption of Organic Compounds. Environ. Sci. Technol. 33, 3225-3233.

Kemmer, F.N. (editor), The NALCO Water Handbook, 2nd ed. Nalco Chemical Company, McGraw-Hill Book Company, New York, 1988.

Kilduff, J. E., Karanfil, T., Weber, W. J., 1998. TCE Adsorption by GAC preloaded with humic substances: effects of molecular weight. J Am Water Works Assoc. 90, 76-89

Kim, C., Lee, S. I., Hwang, S., Cho, M., Kim, H. S., Noh, S. H., 2005. Removal of geosmin and 2-methylisoboneol (2-MIB) by membrane system combined with powdered activated carbon (PAC) for drinking water treatment. Journal of Water Process Engineering 4, 91-98.

Koplin, D.W., Kalkhoff, S.J., Goolsby D.A., Sneck-Fahrer D.A., Thurman E.M., 1997. Occurrence of selected herbicides and herbicide degradation products in lowa's ground water. Groundwater 35, 679-688.

Leenheer, J. A., 2007. Progression from model structures to molecular structure of natural organic matter components. Annals of Environmental Science 1, 57-68. 
Li, Q., Elimelech, M., 2004. Natural organic matter fouling and chemical cleaning of nanofiltration membranes. Water Science and Technology 4, 245-251.

Li, Q., Elimelech, M., 2006. Synergistic effects in combined fouling of a loose nanofiltration membrane by coloidal materials and natural organic matter. Journal of Membrane Science 278, 72-82.

Li, Q., Snoeyink, V. L., Mariãas, B. J., Campos, C., 2003. Elucidating competitive adsorption mechanisms of atrazine and NOM using model compounds. Water Research 37, 773-784.

Listiarini, K., Sun, D. D., Leckie, J. O., 2009. Organic fouling of nanofiltration membranes: Evaluating the effects of humic acid, calcium, alum coagulant and their combinations on the specific cake resistance. Journal of Membrane Science 332, 56-62.

Liu, J., Li, Y., Li, K., 2013.Optimization of preparation of microporous activated carbon with Mondal characteristics. Journal of Environmental Chemical Engeneering 3, 389-397.

Matsui, Y., Ando, N., Sasaki, H., Matsushita, T., Ohno, K., 2009. Branched pore kinetic model analysis of geosmin adsorption on super-powdered activated carbon. Water Research 43, 3095-3103.

Matsui, Y., Ando, N., Yoshida, T., Kurotobi, R., Matsushita, T., Ohno, K., 2011. Modeling high adsorption capacity and kinetics of organic macromolecules on super-powdered activated carbon. Water Research 45, 1720-1728.

Matsui, Y., Fukuda, Y., Murase, R., Aoki, N., Mima, S., Inoue, T., Matsushita, T., 2004. Micro-ground powdered activated carbon for effective removal of natural organic matter during water treatment. Water Science and Technology: Water Supply 4, 155-163.

Matsui, Y., Nakao, S., Tanigushi, T., Matsushita, T., 2013. Geosmin and 2-methylisoborneol removal using superfine powdered activated carbon: shell adsorption and branched-pore kinetic model analysis and optimal particle size. Water Research 47, 2873-80.

Matsui, Y., Yoshida, T., Nakao, S., Knappe, D. R. U., Matsushita, T., 2012. Characteristics of competitive adsorption between 2-methylisoborneol and natural organic matter on superfine and conventionally sized powdered activated carbons. Water Research 43, 4741-4749.

Mondal, S., Sinha, K., Aikat, K., Halder, G., 2015. Adsorption thermodynamics and kinetics of ranitidine hydrochloride onto superheated steam activated carbon derived from mung bean husk. Journal of Environmental Chemical Engineering 1, 187-195.

Najm, I. N., Snoeyink, V. L., Suidan, M. T., Lee, C. H., Richard, Y., 1990. Effect of particle size and background natural organics on the adsorption efficiency of PAC. Journal of American Water Works Association 82, 6572.

Partlan, E., Davis, K., Ren, Y., Apul, O. G., Mefford, O., Karanfil, T., Ladner, D. A., 2015. Effect of bead milling on chemical and physical 
characteristics of activated carbons pulverized to superfine sizes. Water Research 89, 161 - 170.

Pendleton, P., Wong, S. H., Schumann, R., Levay, G., Denoyel, R.,Rouquero, J., 1997. Properties of activated carbon controlling 2methylisoborneol adsorption. Carbon 35, 1141-1149.

Pereira, W.E., Roast, C.E., 1990. Occurrence, distributions and transport of herbicides and their degradation products in the lower Mississippi River and its tributaries. Environ. Sci. Technol. 24, 1400-1406.

Sardella, F., Gimenez, M., Navas, C., Morandi, C., Deiana, C., Sapag, K., 2015. Conversion of viticultural industry wastes into activated carbons for removal of lead and cadmium. Journal of Environmental Chemical Engeneering 1, 253-260.

Seidel, A., Elimelech, M., 2002. Coupling between chemical and physical interactions in natural organic matter (NOM) fouling of nanofiltration membranes: implications for fouling control. Journal of Membrane Science 203, 245-255.

Snoeyink, V. L., Chen, A. S. C., 1985.Removal of organic micropollutants by coagulation and adsorption. The Science of the Total Environment 47, 155-167.

Sontheimer, H., Crittenden, J., Summers, R., 1988. Activated Carbon for Water Treatment, Second Edition, DVGW-Forschungsstelle am EnglerBuntelnstitut der Universitat Karlsruhe, West Germany.

Wigmans, T., (1989). Industrial aspects of production and use of activated carbons. Carbon 27, 13-22.

Williams, J., Goel, R., Flora, J., Vidic, R., 2005. Investigating role of growing adsorbent bed in a dead-end PAC/UF process. Journal of Environmental Engineering 131, 1583-1588.

Yiantsios, S. G., Karabelas, A. J., 2001. An experimental study of humid acid and powdered activated carbon deposition on UF membranes and their removal by backwashing. Desalination 140, 195-209.

Yoon, Y., Westerhoff, P., Snyder, S. A., Wert, E. C., 2006. Nanofiltration and ultrafiltration of endocrine disrupting compounds, pharmaceuticals and personal care products. Journal of Membrane Science 270, 88-100.

Yu, J. Yang, M., Lin, T., Guo, Z., Zhang, Y., Gu, J., Zhang, S., 2007. Effects of surface characteristics of activated carbon on the adsorption of 2methylisobornel (MIB) and geosmin form natural water. Separation and Purification Technology 56, 363-370.

Zhu, X., Elimelech, M., 1997. Colloidal fouling of reverse osmosis membranes: measurements and fouling mechanisms. Environ. Sci. Technol. 31, 3654-3662. 
621 Table

622

623 Table 1: Surface area, external surface area, particle size, $\mathrm{pH}_{\mathrm{pzc}}$ and oxygen content of PACs 624 and S-PACs (Partlan et al., 2015).

\begin{tabular}{|c|c|c|c|c|c|}
\hline Carbon & $\begin{array}{c}\text { Specific } \\
\text { Surface } \\
\text { Area } \\
\left(\mathrm{m}^{2} / \mathrm{g}\right) \\
\end{array}$ & $\begin{array}{c}\text { Specific } \\
\text { External } \\
\text { Surface } \\
\text { Area }\left(\mathrm{m}^{2} / \mathrm{g}\right)\end{array}$ & $\begin{array}{c}\text { Particle } \\
\text { Size } \\
(\mathrm{nm})\end{array}$ & $\mathrm{pH}$ & $\begin{array}{c}\text { Oxygen } \\
\text { Content (\%) }\end{array}$ \\
\hline \multicolumn{6}{|c|}{ 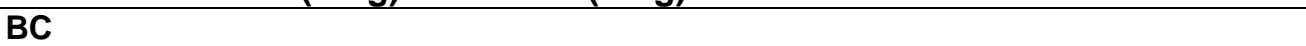 } \\
\hline PAC & 644 & 0.24 & 12300 & 10.37 & 2.41 \\
\hline 1 pass & 777 & 4.78 & 628 & 9.31 & 2.79 \\
\hline $15 \mathrm{~min}$ & 786 & 6.95 & 431 & 9.09 & 3.51 \\
\hline $30 \mathrm{~min}$ & 857 & 7.53 & 398 & 8.92 & 4.19 \\
\hline $1 \mathrm{hr}$ & 872 & 9.12 & 329 & 8.07 & 5.23 \\
\hline $2 \mathrm{hrs}$ & 642 & 9.10 & 329 & 8.10 & 5.87 \\
\hline $6 \mathrm{hrs}$ & 762 & 12.00 & 230 & 7.75 & 7.86 \\
\hline \multicolumn{6}{|l|}{ WD } \\
\hline PAC & 1676 & 0.26 & 11300 & 6.20 & 7.14 \\
\hline 1 pass & 1642 & 2.54 & 1183 & 6.25 & 7.25 \\
\hline $5 \mathrm{~min}$ & 1575 & 3.30 & 1287 & 6.03 & 7.80 \\
\hline $10 \mathrm{~min}$ & 1542 & 4.51 & 665 & 5.72 & 7.85 \\
\hline $20 \mathrm{~min}$ & 1521 & 5.08 & 590 & 5.82 & 8.30 \\
\hline $1 \mathrm{hrs}$ & 1269 & 6.11 & 491 & 5.11 & 9.15 \\
\hline \multirow{2}{*}{\multicolumn{6}{|c|}{ CS }} \\
\hline & & & & & \\
\hline PAC & 1027 & 0.26 & 11300 & 10.79 & 3.38 \\
\hline 1 pass & 1134 & 3.90 & 770 & 10.73 & 3.71 \\
\hline 2 pass & 895 & 4.92 & 610 & 10.44 & 3.84 \\
\hline $5 \min$ & 932 & 4.94 & 633 & 10.57 & 3.91 \\
\hline $10 \mathrm{~min}$ & 938 & 4.86 & 617 & 10.47 & 3.99 \\
\hline $20 \mathrm{~min}$ & 1047 & 5.18 & 579 & 10.33 & 4.06 \\
\hline $4 \mathrm{hrs}$ & 1097 & 8.98 & 334 & 8.00 & 5.38 \\
\hline
\end{tabular}

625 


\section{Figure Captions}

629 Fig. 1. Schematic of the direct-flow MF setup (Millipore).

630 Fig. 2. Flux measurements for the $1 \mathrm{mg} \mathrm{BC}$ carbon coated MF membranes with (a) SRNOM, $631 \mathrm{NaHCO}_{3}$ and $\mathrm{NaCl}$ and (b) $\mathrm{SRNOM}, \mathrm{Ca}^{2+}, \mathrm{NaHCO}_{3}$ and $\mathrm{NaCl}$. In all the experiments the pH 632 was adjusted to 7.0.

633 Fig. 3. SEM images of BC 1 Pass (a) 500X magnification and (b) 5,000X magnification as 634 well as BC 6 hours (c) 500X magnification and (d) 5,000X magnification, deposited on the 635 MF membrane surface. The white scale bar is $\mathbf{2 0} \boldsymbol{\mu m}$ long.

636 Fig. 4. Normalized atrazine concentration (measured concentration divided by the $15 \mu \mathrm{g} / \mathrm{L}$ 637 feed concentration) after filtration with $1 \mathrm{mg} \mathrm{BC}$ carbon coated MF membranes and feed 638 solution (a) DDI water (b) $\mathrm{SRNOM}, \mathrm{NaHCO}_{3}$ and $\mathrm{NaCl}$ and (c) $\mathrm{SRNOM}, \mathrm{Ca}^{2+}, \mathrm{NaHCO}_{3}$ and $639 \mathrm{NaCl}$. In all the experiments the $\mathrm{pH}$ was adjusted to 7.0.

640 Fig. 5. Normalized atrazine concentration (measured concentration divided by the $15 \mu \mathrm{g} / \mathrm{L}$ feed concentration) after filtration with (a) WD carbon and (b) CS carbon 1 mg MF coated membranes and feed solution with SRNOM, $\mathrm{Ca}^{2+}, \mathrm{NaHCO}_{3}$ and $\mathrm{NaCl}$. In all the experiments the $\mathrm{pH}$ was adjusted to 7.0 .

Fig. 6. BC carbon batch adsorption kinetics of atrazine with (a) DDI water and (b) SRNOM, $\mathrm{NaHCO}_{3}$ and $\mathrm{NaCl}$. In all the experiments the $\mathrm{pH}$ was adjusted to 7.0.

Fig. 7. Comparison between characterization data as (a) oxygen content, (b) surface area, (c) particle size and (d) external surface area with atrazine removal (\%) for the carbons BC, CS and WD $1 \mathrm{mg}$ coated MF membranes. The feed water contained SRNOM, $\mathrm{Ca}^{2+}, \mathrm{NaHCO}_{3}$ and $\mathrm{NaCl}$ and the $\mathrm{pH}$ was adjusted to 7.0.

650 Fig. 8. Comparison between atrazine removal and normalized permeate flux obtained with

$6511 \mathrm{mg} \mathrm{BC}$, WD and CS S-PAC coated MF membranes. The feed water contained SRNOM, $652 \mathrm{Ca}^{2+}, \mathrm{NaHCO}_{3}$ and $\mathrm{NaCl}$ and the $\mathrm{pH}$ was adjusted to 7.0. 


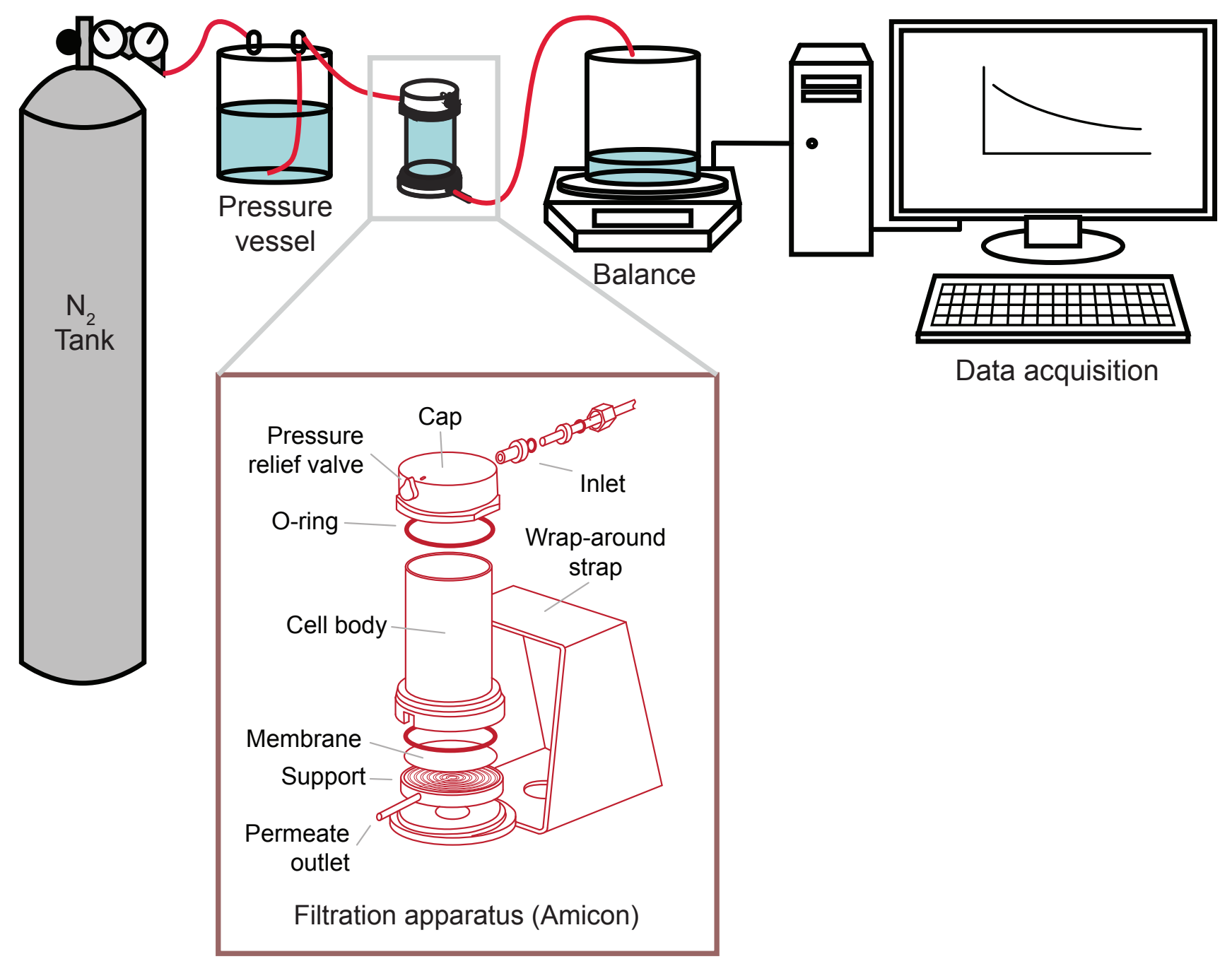



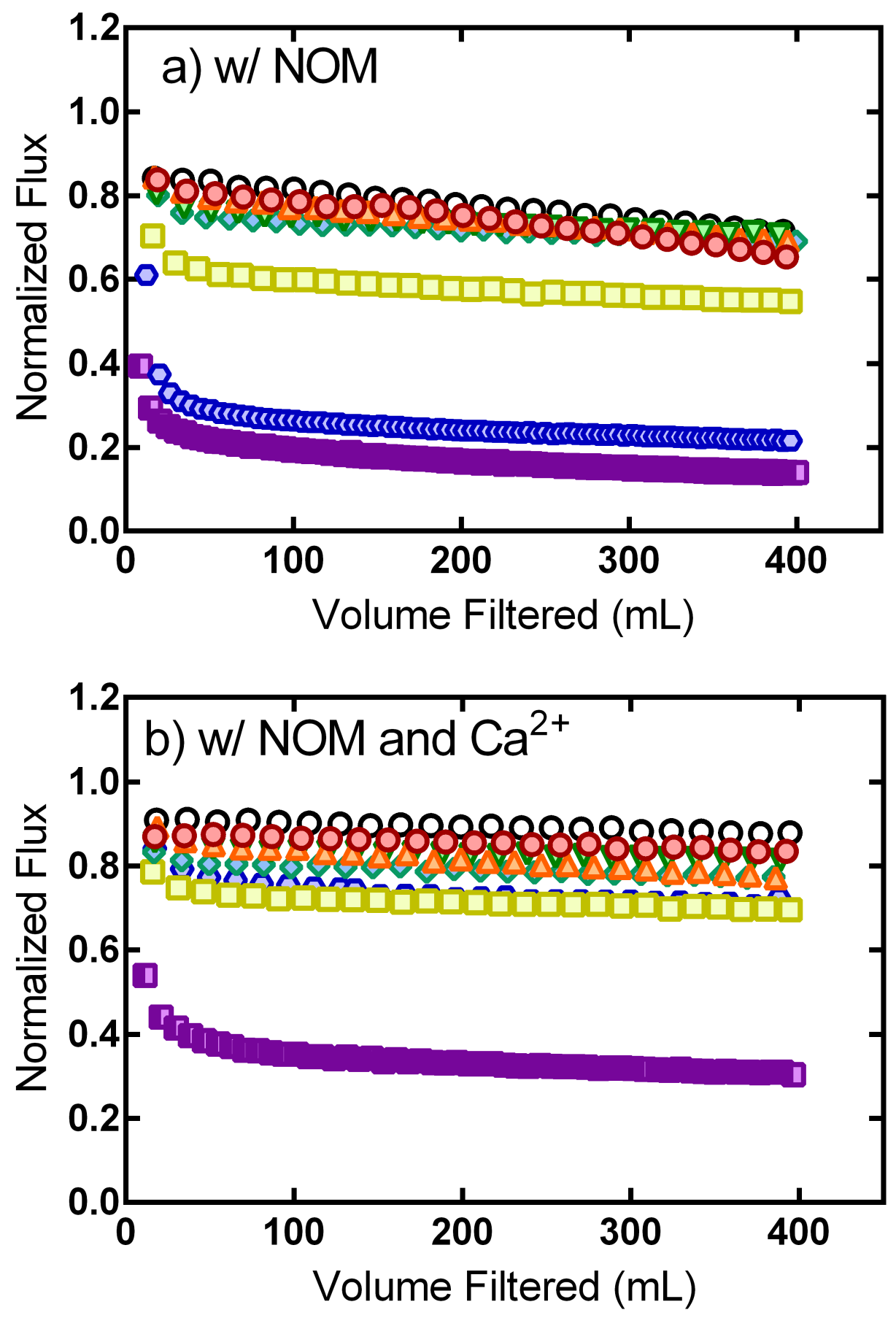

- BC-PAC

․ BC-1 hr

$\triangle$ BC-1 pass $\quad$ BC-2 hours

$\nabla$ BC-15 min $\square$ BC-6 hours

- BC-30 min $O$ No carbon 

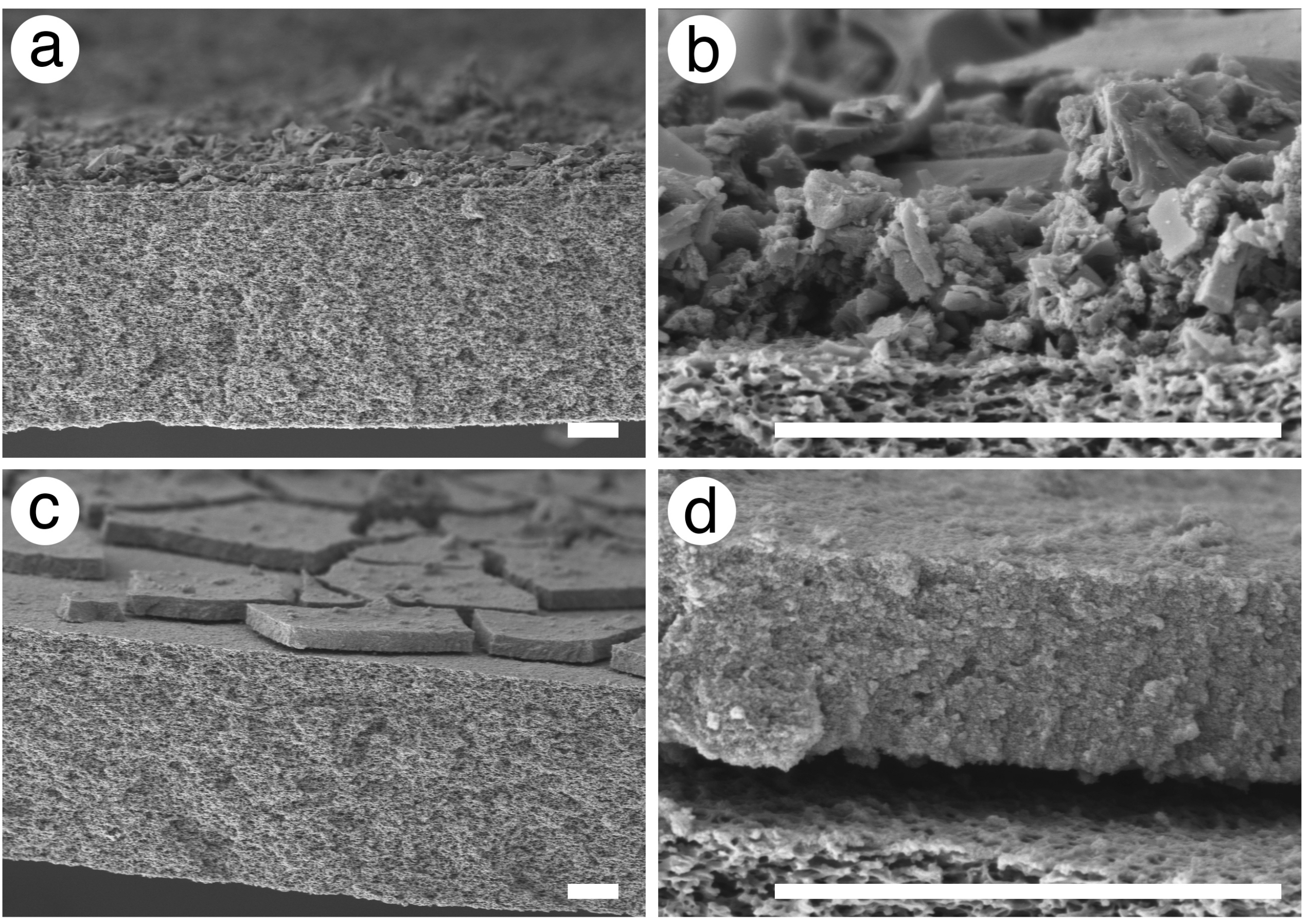

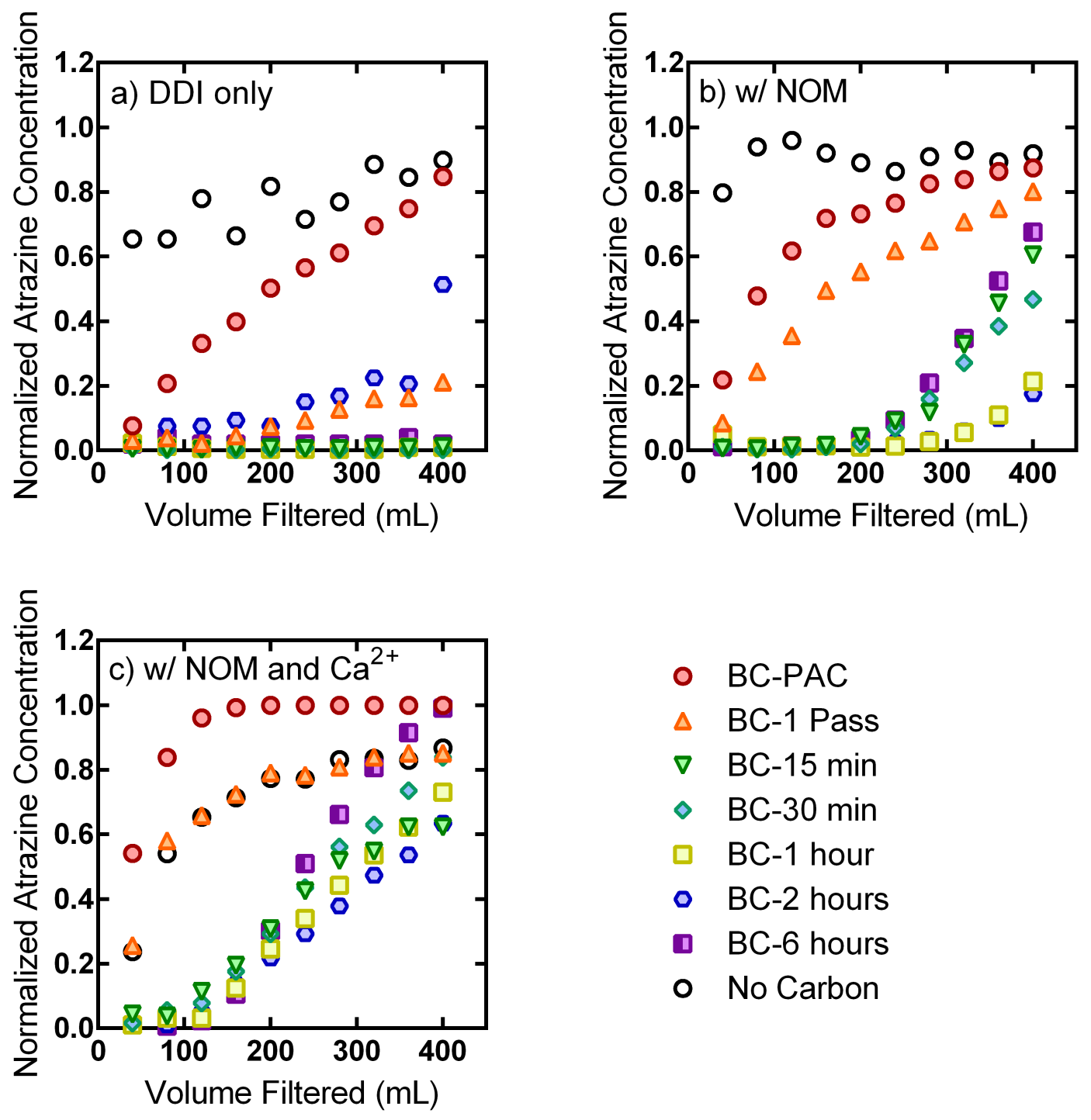

- BC-PAC

$\triangle$ BC-1 Pass

$\nabla \quad$ BC-15 min

- BC-30 min

- BC-1 hour

- BC-2 hours

- BC-6 hours

- No Carbon 


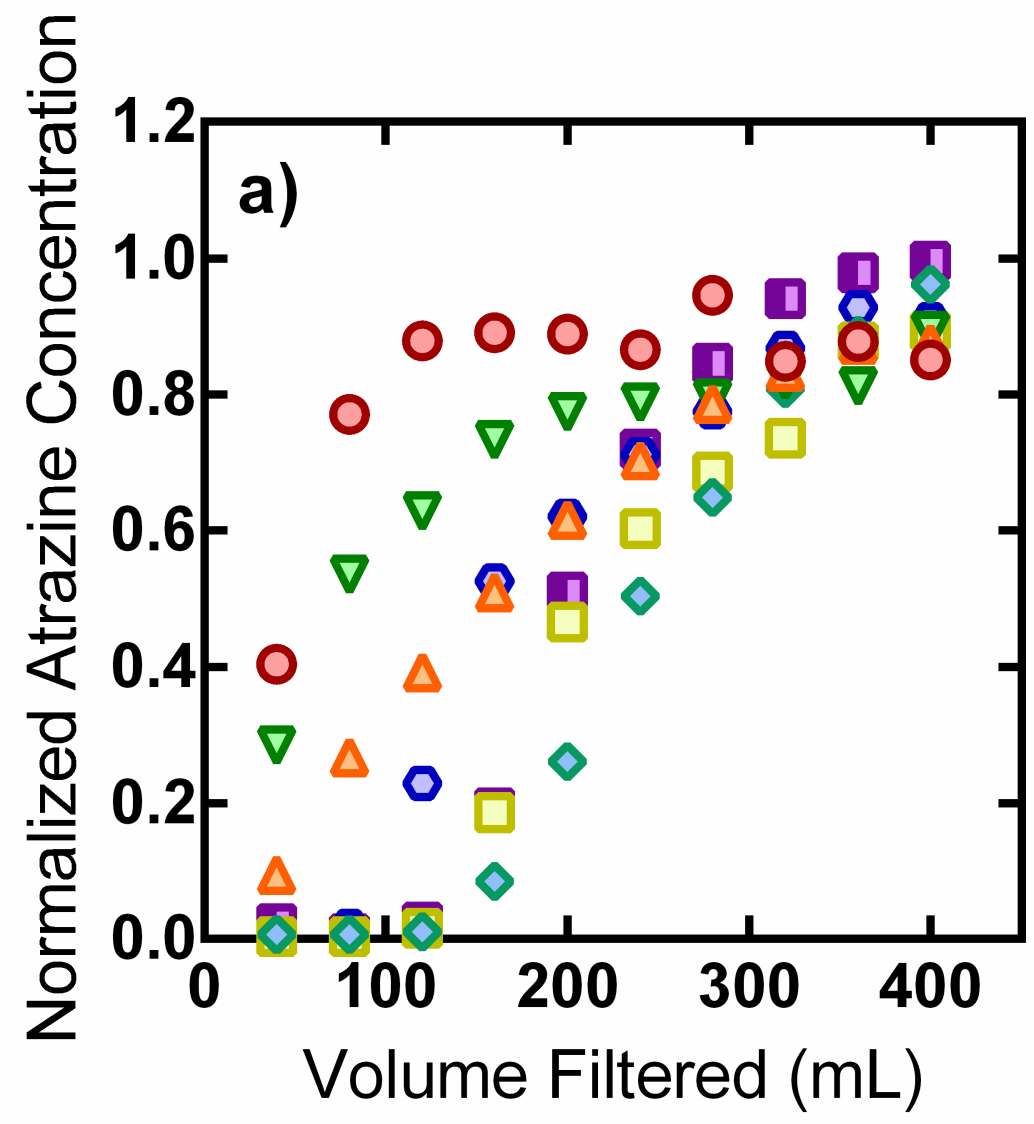

- WD-PAC

$\triangle$ WD-1 Pass

$\nabla$ WD-5 min

- WD-10 min

- WD-20 min

- WD-1 hour

a WD-6 hours

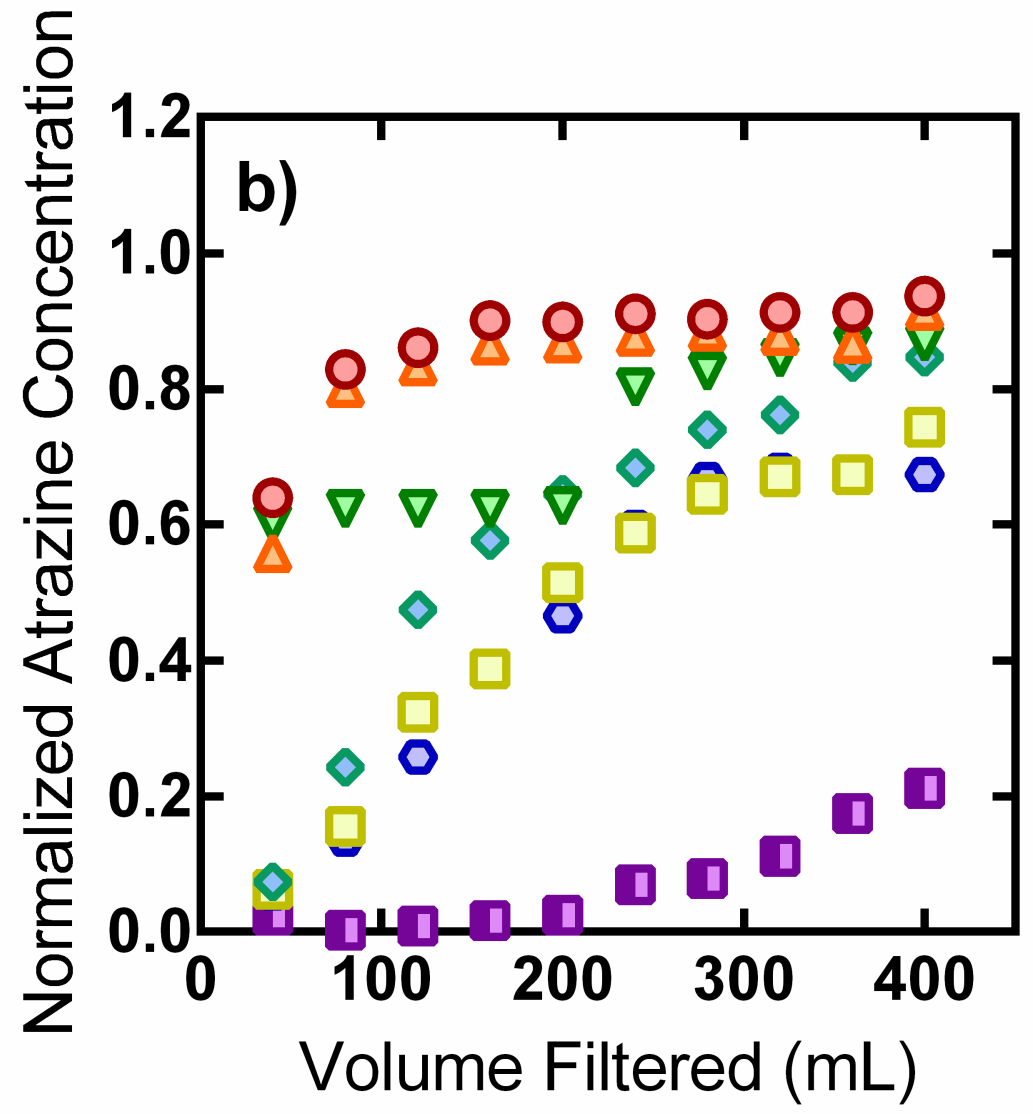

- CS-PAC

$\triangle$ CS-1 Pass

$\nabla$ CS-2 Pass

- CS-5 min

- CS-10 min

- CS-20 min

- CS-4 hours 
a) DDI only

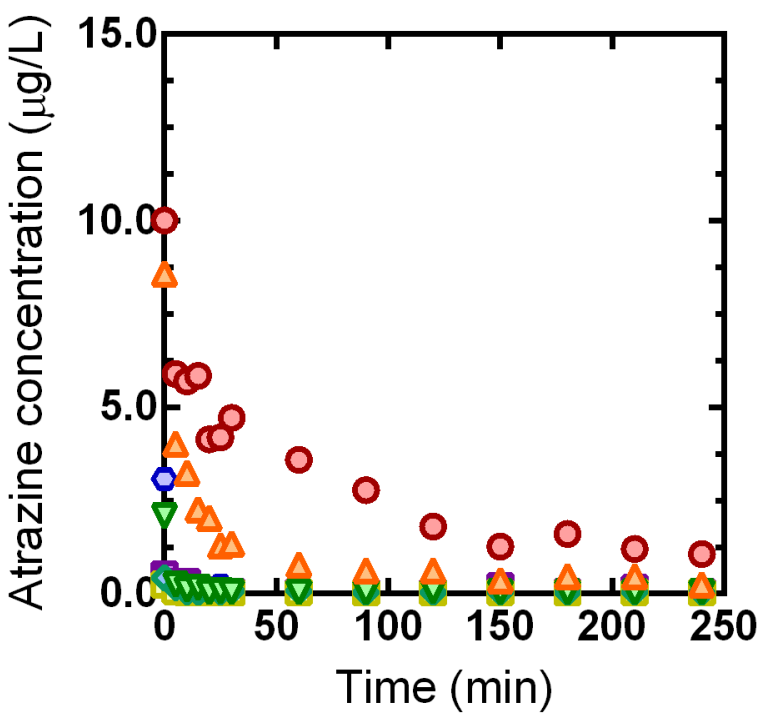

b) w/ NOM

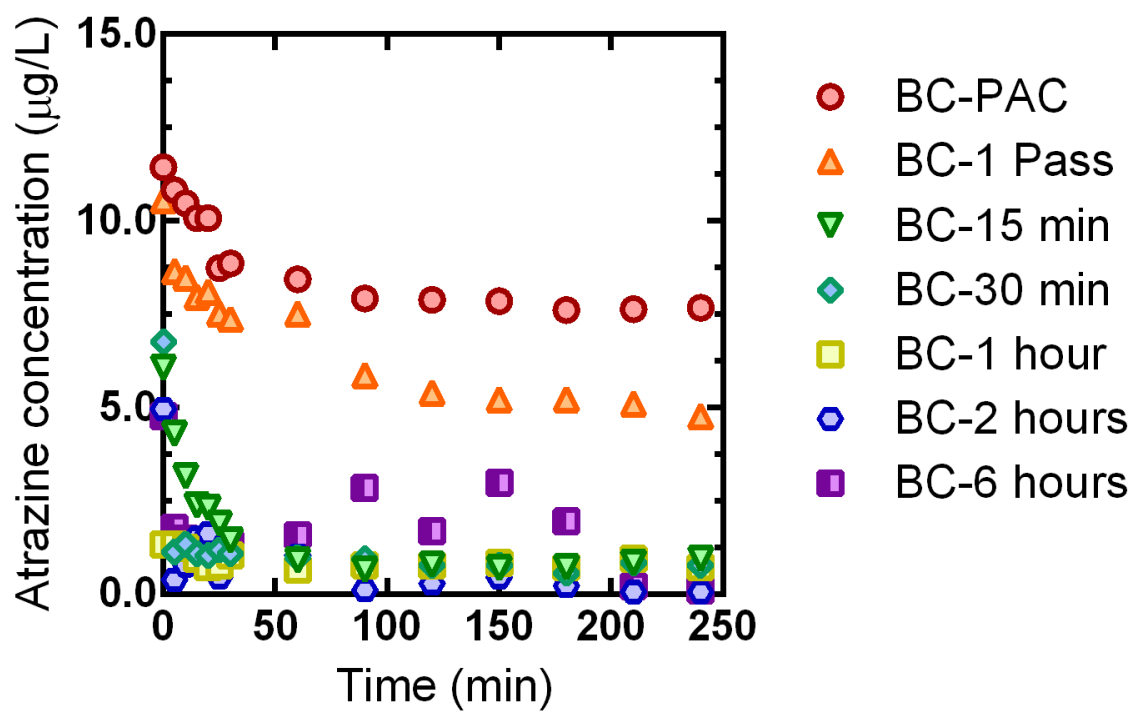



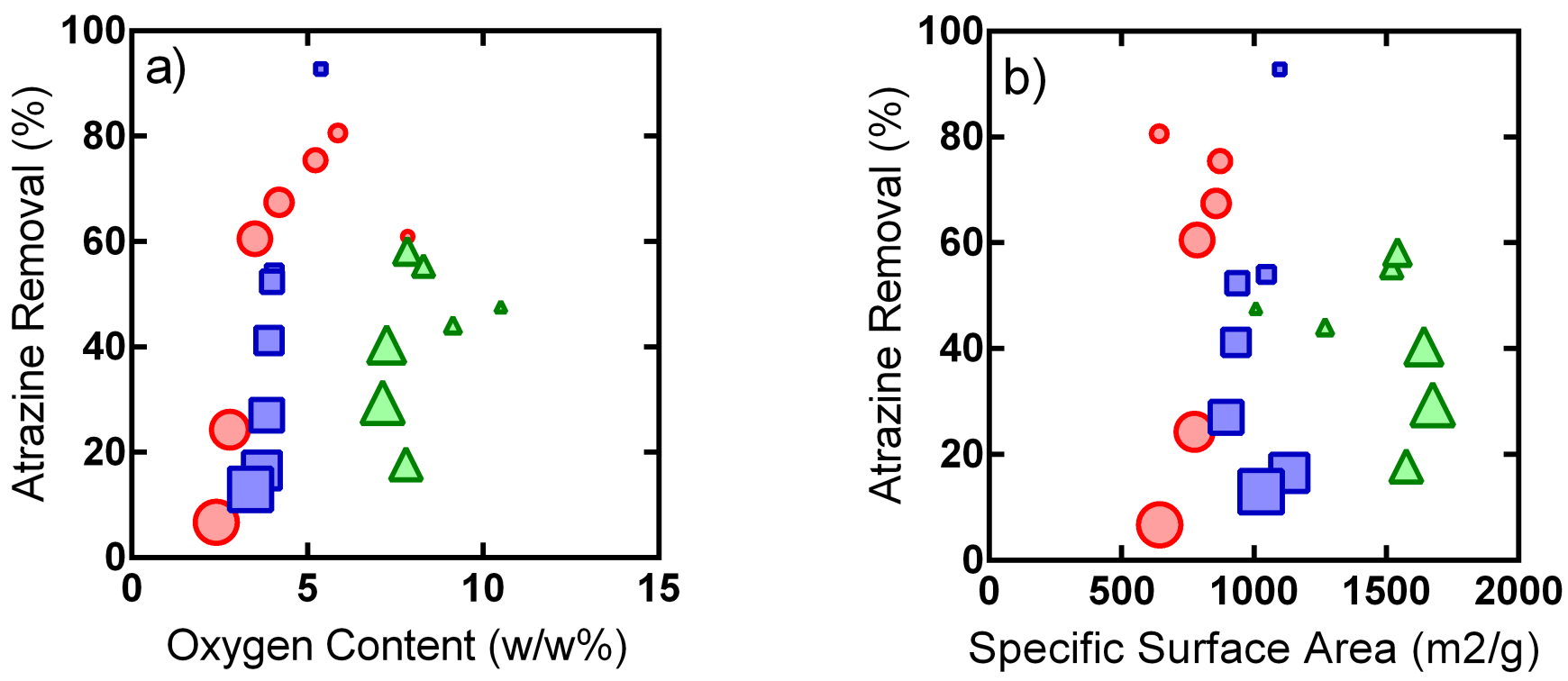

Specific Surface Area (m2/g)
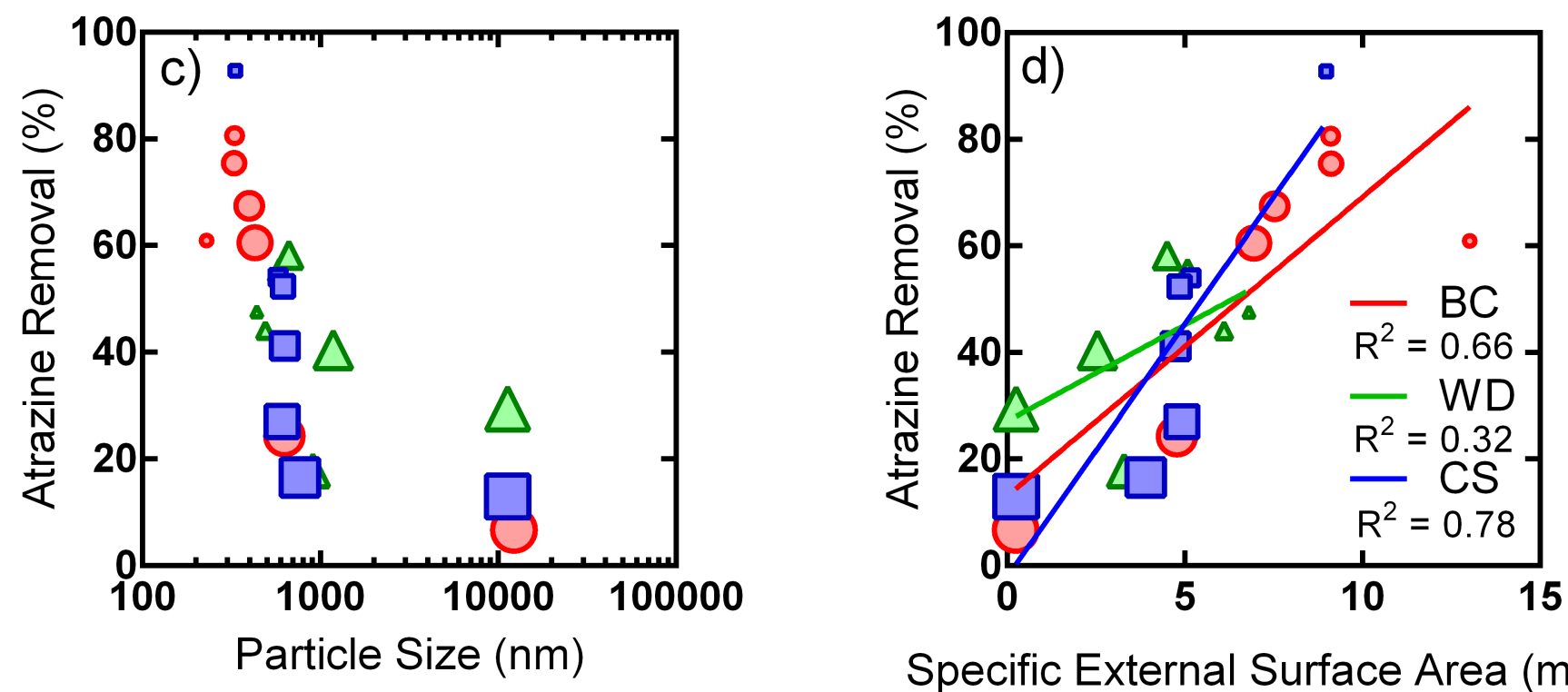

Specific External Surface Area $\left(\mathrm{m}^{2} / \mathrm{g}\right)$

\begin{tabular}{|c|c|c|c|}
\hline BC-PAC & $\triangle W D-P A C$ & $\square$ & CS-PAC \\
\hline BC-1 Pass & $\triangle$ WD-1 Pass & $\square$ & CS-1 Pass \\
\hline BC-15 min & WD-5 min & $\square$ & CS-2 Pass \\
\hline BC-30 min & WD-10 min & 口 & CS-5 min \\
\hline BC-1 hour & WD-20 min & 口 & CS-10 min \\
\hline BC-2 hours & $\Delta$ WD-1 hour & 口 & CS-20 min \\
\hline BC-6 hours & - WD-6 hours & - & CS-4 hours \\
\hline
\end{tabular}




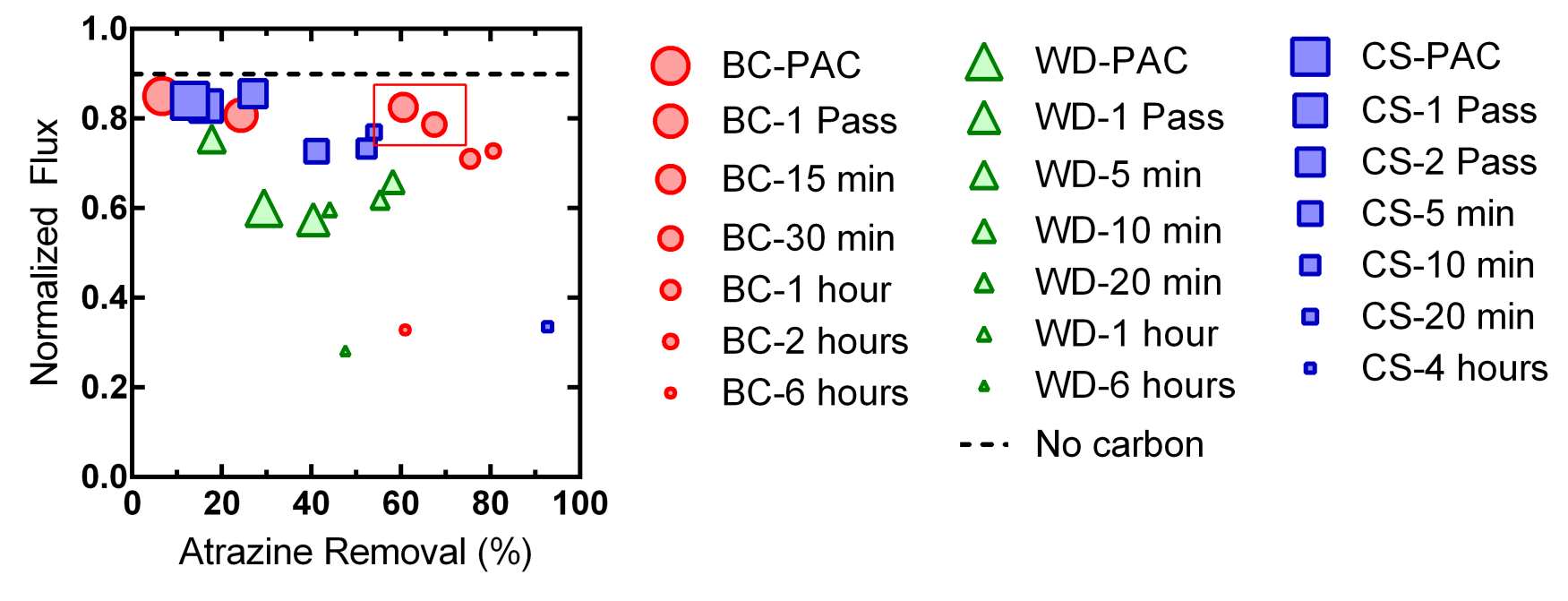



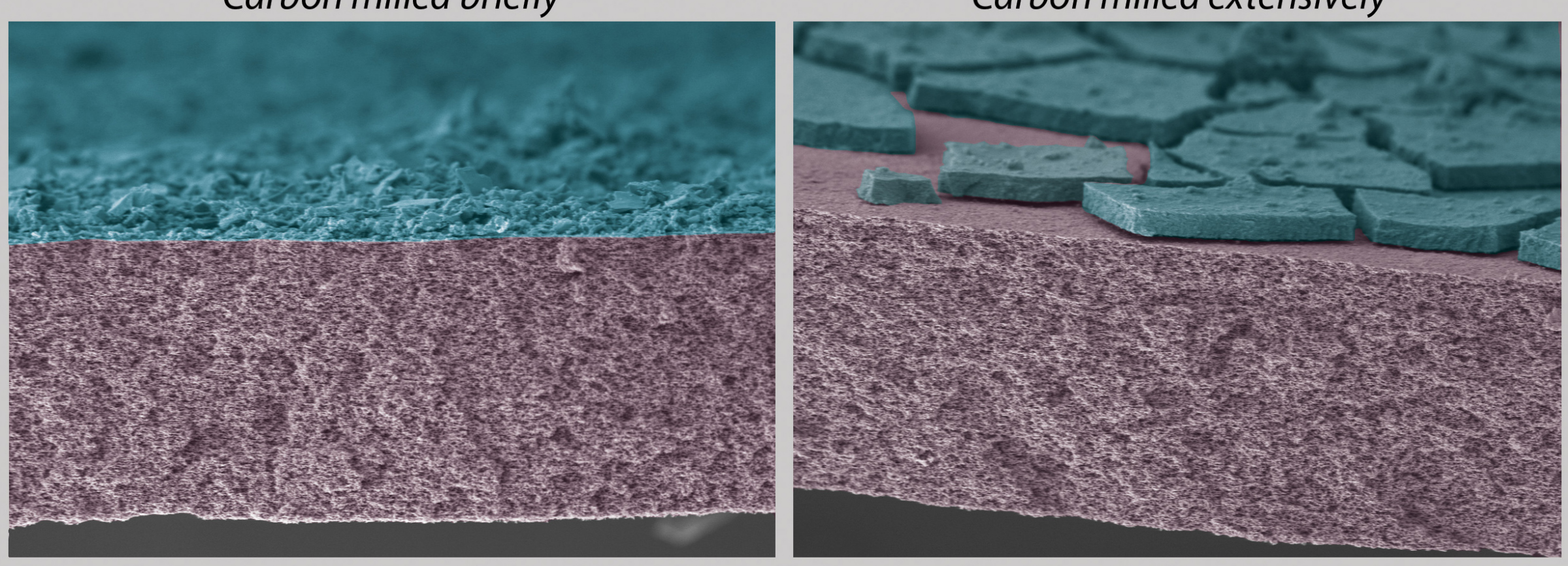

Activated-carbon-coated membranes (dried) 